\title{
Repenser la communication dans les organisations
}

Luc Bonneville, Sylvie Grosjean (Dirs.) Paris : L'Harmattan, coll.

Communication des organisations, 2007, 294 pages

\section{Elizabeth Gardère}

\section{OpenEdition}

Journals

Édition électronique

URL : http://journals.openedition.org/communicationorganisation/539

DOI : 10.4000/communicationorganisation.539

ISSN : $1775-3546$

Éditeur

Presses universitaires de Bordeaux

Édition imprimée

Date de publication : 1 juin 2008

Pagination : 152-153

ISBN : 978-2-86781-506-5

ISSN : 1168-5549

Référence électronique

Elizabeth Gardère, "Repenser la communication dans les organisations », Communication et organisation [En ligne], 33 | 2008, document 15, mis en ligne le 01 juin 2008, consulté le 21 septembre 2020. URL : http://journals.openedition.org/communicationorganisation/539 ; DOI : https://doi.org/ 10.4000/communicationorganisation.539 
Bibliographie

\title{
Repenser la communication dans les organisations
}

\author{
Luc Bonneville, Sylvie Grosjean (Dirs.)
}

Paris : L'Harmattan, coll. Communication des organisations, 2007, 294 pages.

L'originalité de cet ouvrage, sous la direction de Luc Bonneville et Sylvie Grosjean de l'université d'Ottawa (Canada), réside dans le regard croisé de chercheurs français et canadiens sur le lien entre communication et organisation. L'étude de ce lien, de sa création à ses mutations, offre une myriade de perspectives pour les recherches empiriques et pratiques. Aussi est-il important de préciser que le choix de la problématique qui traverse ce collectif est le sens en organisation.

Réunis autour du projet de compréhension des organisations et des phénomènes communicationnels qui les constituent, les analyses recueillies dans Repenser la communication dans les organisations se structurent autour de quatre axes. Certains auteurs convoquent la question de la production du sens en organisation qui concourre à la construction collective du sens et à la dynamique collective (Vacher, Gramaccia, Brassac et Fixmer). D'autres envisagent les connaissances comme levier organisationnel (Robillard, Grosjean). D'aucuns portent leurs recherches sur la technologisation des pratiques et son rapport à l'action (Bonneville, Millerand). Enfin, quels que soient les processus communicationnels, le sujet reste au cœur de l'organisation. Connaître et reconnaître la place du sujet ouvre la voie, notamment ici, à l'approche humaniste (Davila-Gomez et Morin, Lagacé et Tougas).

Des concepts tels que le sens, l'interprétation, la connaissance, l'action dans des contextes organisés, nourrissent les contributions et permettent de dépasser le paradigme de l'informativité et les conceptions quantitatives au bénéfice du paradigme de la communicabilité et des processus interactionnels.

L'objectif de Luc Bonneville et Sylvie Grosjean est atteint lorsque la diversité des approches s'exprime, tant par l'appartenance des 
contributions à des champs disciplinaires variés (communication, gestion, sociologie...), que par la manière dont les auteurs se saisissent de la problématique du sens en organisation. Qu'il s'agisse $\mathrm{du}$ lien pragmatique en organisation, du lien entre mémoire, communication et organisation, voire des liens noués lors des interactions, cet ouvrage collectif contribue à la collaboration francophone des recherches en sciences de l'information et de la communication et à leur rayonnement.

Elizabeth Gardère 